\title{
EDITORIAL
}

\section{In This Issue: Mental Health and Care Management, Health Behavior Change, and Reflection in Primary Care}

\author{
Kurt C. Stange, $M D, P b D$, Editor \\ Ann Fam Med 2008;6:2-3. DOI: 10.1370/afm.803.
}

A rticles in this issue deepen our understanding of mental health care, care management, health behavior change intervention, and reflective practice. This issue is accompanied by a supplement devoted to resident research and includes a thoughtprovoking editorial by one of the fathers of modern family medicine.

Four mental health studies challenge us to develop systems to meet the needs of patients. These studies identify an interesting pattern of depressed patients' perceptions of the necessity or harmfulness of antidepressant medications ${ }^{1}$; assess from multiple vantage points the benefit of involving care managers for patients seen in a psychiatric emergency department ${ }^{2}$; evaluate the relationship between intimate partner violence, depression, and posttraumatic stress disorder in pregnant Latina women ${ }^{3}$; and identify physicianperceived barriers to implementing a care management program for depressed patients. ${ }^{4}$

In another interesting qualitative study, the voice of the practicing physician is scrutinized to discover how patients' socioeconomic status affects clinical management decisions. ${ }^{5}$ Like another study on this topic in last year's Annals, ${ }^{6}$ this study shows that finances and health care coverage are not abstractions but affect how patients are cared for every day by clinicians trying to do their best for individual patients within an inequitable system.

Ohman-Strickland et $\mathrm{al}^{7}$ examine differences in diabetes care in practices with and without a nursepractitioner. It is not possible to assert that the nurse-practitioner is the cause of the observed differences, but from this study, it is apparent that something different is going on in practices that engage a nurse-practitioner.

Patient's trust and commitment to their family physician strengthen the patient-physician relationship and are associated with adherence and healthy eating in this study by Berry and colleagues. ${ }^{8}$

Rothemich and colleagues ${ }^{9}$ conduct a cluster randomized trial in a practice-based research network to evaluate the commonly recommended but rarely empirically evaluated use of smoking status as a routine vital sign. They find that this simple intervention results in a modest increase in simple advice to quit but not in more intensive counseling.

A meta-analysis by Richardson and colleagues ${ }^{10}$ is the focus of this issue's Annals Journal Club. ${ }^{11}$ By bringing together the findings of 9 studies, they find that pedometer-based walking programs result in a modest weight loss, with longer interventions resulting in greater weight loss.

Two essays reflect on some of the challenges and lessons that can arise when clinicians are in relationship with patients. Selwyn ${ }^{12}$ asks us to accompany him on a short subway ride that takes us on a much longer journey: a journey that goes beyond mental shortcuts based on stereotypes to a place of openness to patients' stories. An essay by Allen ${ }^{13}$ describes the author's search for meaningful purpose while struggling with his own preconceptions and expectations in his work with native patients.

We also are pleased to feature a Resident Research Supplement ${ }^{14}$ that give us a snapshot of the current state of resident research and an analysis by the 2 guest editors. ${ }^{15}$ I am grateful to the guest editors, the American Academy of Family Physicians Foundation that funded this effort, and to Annals Senior Associate Editor, Bill Phillips, who ran the Annals portion of the review process. In particular, I wish to thank the residents and faculty members who submitted manuscripts and participated in the first stage of the peer-review process.

Finally, an editorial by Ian McWhinney ${ }^{16}$ in this issue throws out an important challenge to journals 
that seek to publish clinical research. Recalling some of the great discoveries from research in general practice, Dr McWhinney suggests journals need to develop standards that provide space for novel findings based on clinical observation. He suggests that plausibility, support from the basic sciences and appropriate literature, clarity of the concepts, and reproducibility of the procedures may be more important than traditional methodological standards if research journals are to provide a forum for, rather than squelch, new discoveries. The Annals is enthusiastic about seeking out and supporting the dissemination of the kind of emergent discoveries based on careful clinical observation that Dr McWhinney describes. We look forward to receiving more submissions of this kind and to asking our peer reviewers to consider them in particular for the potential importance and novelty of their discoveries.

Please share your insights by joining the Annals online discussion at http://www.AnnFamMed.org.

\section{References}

1. Aikens JE, Nease DE, Klinkman MS. Explaining patient beliefs about the necessity and harmfulness of antidepressants. Ann Fam Med. 2008;6(1):23-29.

2. Griswold KS, Zayas LH, Pastore PA, et al. Primary care after psychiatric crisis: a qualitative analysis. Ann Fam Med. 2008;6:(1)38-43.

3. Rodriguez MA, Heilemann M, Fielder E, Ang A, Nevarez F, Mangione C. Intimate partner violence, depression, and PTSD among pregnant Latina women. Ann Fam Med. 2008;6:(1)44-52.
4. Nutting PA, Gallagher K, Riley K, et al. Care management for depression in primary care practice: findings from the RESPECTDepression Trial. Ann Fam Med. 2008;6:(1)30-37.

5. Bernheim SM, Ross JS, Krumholz HM, Bradley EH. The influence of patients' socioeconomic status on clinical management decisions: a qualitative study. Ann Fam Med. 2008;6:(1)53-59.

6. Meyers DS, Mishori R, McCann J, Delgado J, O'Malley A, Fryer E. Primary care physicians' perceptions of the effect of insurance status on clinical decision making. Ann Fam Med. 2006;4(5):399-402.

7. Ohman-Strickland PA, Orzano AJ, Hudson S, et al. Quality of diabetes care in family medicine practices: influence of nurse-practitioners and physicans' assistants. Ann Fam Med. 2008;6:(1)14-22.

8. Berry LL, Parish J, Janakiraman R, et al. Patients' commitment to their primary physician and why it matters. Ann Fam Med. 2008;6:(1)6-13.

9. Rothemich SF, Woolf SH, Johnson R, et al. The effect on cessation counseling of documenting smoking status as a routine vital sign: an ACORN study. Ann Fam Med. 2008;6:(1)60-68.

10. Richardson CR, Newton TL, Abraham JJ, Sen A, Jimbo M, Swartz AM. A meta-analysis of pedometer-based walking interventions and weight loss. Ann Fam Med. 2008;6:(1)69-77.

11. Pedometers for promoting walking and weight loss. Annals Journal Club. Ann Fam Med. 2008;6:(1):iii.

12. Selwyn PA. The island. Ann Fam Med. 2008;6:(1)78-79.

13. Allen RE. Stuck in the mud. Ann Fam Med. 2008;6:(1)80-82.

14. Carek PJ, Mainous AG III, eds; Phillips WR, supplement ed. Residency research supplement. Ann Fam Med. 2008;6(suppl 1):s1-s36. http://www.annfammed.org/content/vol6/suppl_1.

15. Carek PJ, Mainous AG III. The state of resident research in family medicine: small but growing. Ann Fam Med. 2008;6:(suppl 1) s2-s24.

16. McWhinney I. Assessing clinical discoveries. Ann Fam Med. 2008; $6:(1) 3-5$.

\title{
EDITORIAL
}

\section{Assessing Clinical Discoveries}

\author{
Ian R. McW binney, OC, MD, FRCGP, FCFP, FRCP \\ Centre for Studies in Family Medicine, Schulich School of Medicine \& Dentistry, The University of Western Ontario, London, Ontario
}

Ann Fam Med 2008:6:3-5. DOI: 10.1370/afm.801.

\section{Conflicts of interest: none reported}

\section{CORRESPONDING AUTHOR}

Ian R. McWhinney, MD, Professor Emeritus

Centre for Studies in Family Medicine

The University of Western Ontario

Suite 245, 100 Collip Circle

London, Ontario, N6G 4X8

Canada

irmcwhin@uwo.ca
G eneral practice has a long, though tenuous, history of clinical research, carried out often by single practitioners working with their own patients. Recent experience has convinced me that this is still the case, even though very little clinical research is published in the journals of family medicine and general practice. After a thorough review of the journal's first 2 years, the editors of the Annals of Family Medicine concluded, with good reason, that much had been achieved in most aspects of the journal, but they 